\title{
Surgical Management of Chiari Malformation Type One in Adults
}

\author{
Ahmed M Kersh ${ }^{1 *}$, Ehab A Abdelhaleem ${ }^{1}$ and Hanan Helmy ${ }^{2}$ \\ ${ }^{1}$ Department of Neurosurgery, Cairo University, Egypt \\ ${ }^{2}$ Department of Neurology, Cairo University, Egypt \\ *Corresponding author: Ahmed Mostafa Kersh, Department of Neurosurgery, Cairo University, Egypt
}

Submission: February 25, 2018; Published: March 07, 2018

\begin{abstract}
Introduction: is a malformation of the skull. It consists of a downward displacement of the cerebellar tonsils through the foramen magnum sometimes causing non-communicating hydrocephalus.

Objectives: to assess the value of the surgical management by posterior fossa bony decompression and cautious durotomy, shrinkage of tonsils and duroplasty with fascia lata graft in the clinical and radiological improvement of patients with Chiari malformation type 1.

Patients \& Methods: This is a prospective study included 20 patients with Chiari malformation type I, operated through posterior fossa craniectomy, durotomy in Y-shaped manner, shrinkage of cerebellar tonsils by bipolar electrocautry, duroplasty by fascia lata graft and water tight closure. All patients underwent evaluation clinically and radiologically by CT scanning and MRI brain preoperatively and 3 months after surgery to assess the improvement.

Results: The mean age was 41.5 years ranging from 18 to 65 years. There was a female predominance as the females represented (60\%) and males (40\%). The most common clinical findings presented at diagnosis were headache in 20 patients, neck pain in 18 patients, 12 patients reported good outcome, 4 fair, 4 poor, 10 patients showed marked reduction in syrinx size, 2 mild reduction, 8 no change, 16 patients showed normal level of tonsils postoperatively, and 4 patients were within $5 \mathrm{~mm}$ below foramen magnum.
\end{abstract}

Conclusion: Posterior fossa bony decompression and cautious durotomy, shrinkage of tonsils and duroplasty with fascia lata graft has good clinical and radiological outcome. Watertight closure of dura is recommended to avoid CSF leak and wound infection.

Keywords: Small posterior fossa; Osseous decompression; Dural graft; Syringomyelia

\section{Introduction}

The pathologist Hans Chiari is the first one described Chiari type 1-malformation (CM-1) in 1981 as a caudal descent of the cerebellar tonsils passing through the foramen magnum to the spinal canal at least $5 \mathrm{~mm}$ below the inferior lip of the foramen magnum without involving the brain stem with non-communicating hydrocephalus in some cases. Syringomyelia is seen in $32-73 \%$ of cases with CM-I. This anatomical change can be seen as a result of obstruction of cerebrospinal fluid (CSF) outflow [1-7]. The cerebrospinal fluid outflow is caused by phase difference in outflow and influx of blood in the vasculature of the brain. Chiari 1.5 malformation has been described recently. The difference is the caudal descent of the brain stem in CM type 1.5 but both has the same management $[8,9]$.

Described four congenital malformations that would later became known as the Chiari malformations. The known four varieties of Chiari malformations represent varying degrees of rhombencephalic derivatives involvement [4]. Three of these (types I to III) have progressively more severe herniation of these structures outside the posterior fossa as a common feature. These three types also have in common a pathogenesis that involves loss of free movement of cerebral spinal fluid (CSF) out of the normal outlet channels of the fourth ventricle [4]. Pathological differences between type I and type II can be explained with knowledge of the differences in the timing of the development of the hindbrain herniation [4]. Most common types of hindbrain hernias are congenital but acquired CMs occur and are not rare. Other causes that may be considered are intracranial lesions, especially within the posterior fossa that can cause tonsil herniation outside the posterior fossa [4]. CM-I can cause headaches, muscle weakness in the head and face, fatigue, dizziness, nausea, difficult swallowing, impaired coordination, and, in severe cases, paralysis [10]. Several modalities has been established in surgical treatments of CM-I with controversery about selection. Suboccipital craniectomy is generally accepted but with different companion with laminectomy $\mathrm{C} 1 \pm \mathrm{C} 2$, dural opening with duraplasty, arachnoid opening (lysis of adhesion), tonsils cautery or stenting of the fourth ventricle [10].

\section{Patients and Methods}

This is a prospective study for 20 patients diagnosed as Chiari malformation type I operated up on in the period between March 
2012 to June 2015 at Neurosurgery Department of Cairo University Hospitals. Inclusion criteria were patients between 18-65 years old, symptomatic with progressive course without high medical risk. The study excluded patients out of age range, asymptomatic patients, symptomatic patients with stationary course or patients with severe medical condition.

All patients' data were collected preoperatively regarding age, sex, medical history, present history, general examination, ophthalmologic assessment and full neurological examinations. All patients were investigated by CT brain, MRI brain with follow up by CT brain in the first 24 hours postoperatively and follow up MRI 3 months later.

In this study, after formal consent and discussion of the procedure and the prognosis, all patients were operated through midline neck incision, craniectomy, durotomy in y shaped manner. The immediate postoperative data was evaluated in all patients and then patients were followed subsequently as outpatient, 3-6 months later. The evaluation was done both clinically regarding any improvement or deterioration in the symptomatology and radiologically (MRI \& CT scan) to detect any ventriculomegaly or enlargement of syrinx.

\section{Results}

\section{Age and sex distribution}

The mean age at the time of surgery for the studied group was 41.5 years ranging from 18 to 65 years. There was a female predominance as 12 patients were females $(60 \%)$ and 8 patients were males $(40 \%)$ which provide a female/male ratio of $(1.5 / 1)$ (Table 1 \& 2).

Table 1: Showing number of male and females case.

\begin{tabular}{|c|c|}
\hline Number of female cases & 12 \\
\hline Number of male cases & 8 \\
\hline
\end{tabular}

Table 2: Showing the range of age at diagnosis.

\begin{tabular}{|c|c|}
\hline Number & Range of age of diagnosed patients \\
\hline 10 & $18-30$ \\
\hline 4 & $31-40$ \\
\hline 6 & $41-50$ \\
\hline 0 & $51-65$ \\
\hline
\end{tabular}

\section{Clinical presentation}

Table 3: Showing the presenting clinical picture at diagnosis.

\begin{tabular}{|c|c|c|}
\hline Clinical presentation & Number of patients & Percentage \% \\
\hline Headache & 20 & 100 \\
\hline Neck pain & 18 & 90 \\
\hline Dizziness \& fatigue & 14 & 70 \\
\hline $\begin{array}{c}\text { Extremities numbness \& } \\
\text { parathesia }\end{array}$ & 12 & 60 \\
\hline Weakness of fine movements & 8 & 40 \\
\hline Sphincteric dysfunction & 4 & 20 \\
\hline Cerebellar dysfunction & 4 & 20 \\
\hline
\end{tabular}

The most common clinical findings presented at diagnosis were headache in 20 patients, neck pain in 18 patients, dizziness and fatigue in 14 , extremities numbness and parathesia in 12 patients, weakness of fine movements in 8 patients, sphincteric manifestation in 4 patients, cerebellar dysfunction in 4 patients (Table 3 \& Figure 1).

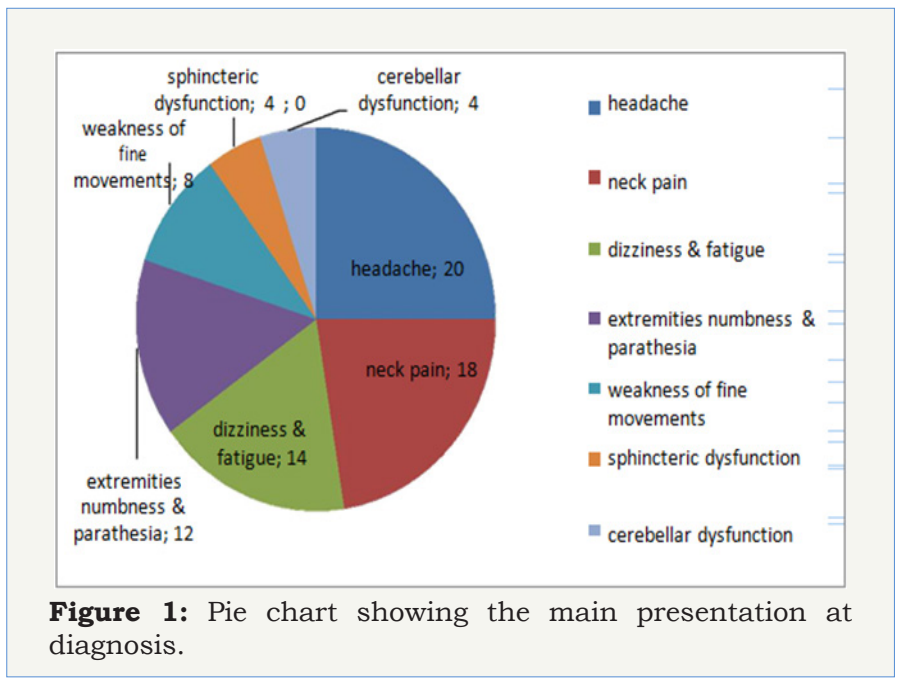

\section{Clinical outcome}

It was assessed as:

a) Good: patients having marked improvement with no residual symptoms causing any sort of disability.

b) Fair: patients having residual symptoms causing mild disability in performing their usual daily activities.

c) Poor: patients having no improvement at all [11] (Table 4).

Table 4: Showing clinical outcome after surgery.

\begin{tabular}{|c|c|}
\hline Number & Clinical outcome \\
\hline 12 & Good \\
\hline 4 & Fair \\
\hline 4 & Poor \\
\hline
\end{tabular}

In this study, 12 patients reported good outcome, 4 fair, 4 poor.

\section{Size of the syrinx}

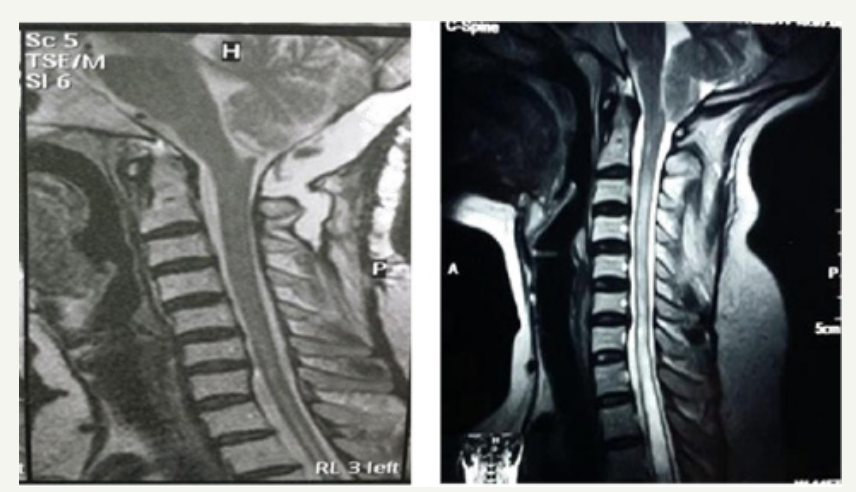

Figure 2: Preoperative/postoperative MRI showing the reduction of syrinx. 
In evaluation of the syrinx size postoperatively in this study, 10 patients showed marked reduction, 2 mild reduction, 8 no change (Figure 2) (Table 5).

Table 5: Showing the size of the syrinx after surgery.

\begin{tabular}{|c|c|}
\hline Number & Size of syrinx \\
\hline 10 & Marked reduction \\
\hline 2 & Mild reduction \\
\hline 8 & No change \\
\hline
\end{tabular}

\section{Level of the tonsils}

In evaluation of the lower border of the tonsils after shrinkage by bipolar electrocautry postoperatively in this study, 16 patients showed normal level, and 4 patients were within $5 \mathrm{~mm}$ below foramen magnum (Table 6).

Table 6: Showing the lower level of tonsils postoperative.

\begin{tabular}{|c|c|}
\hline Number & $\begin{array}{c}\text { Level of tonsils radiologically post- } \\
\text { operative }\end{array}$ \\
\hline 16 & Normal level \\
\hline 4 & Within 5 mm below foramen magnum \\
\hline
\end{tabular}

\section{Discussion}

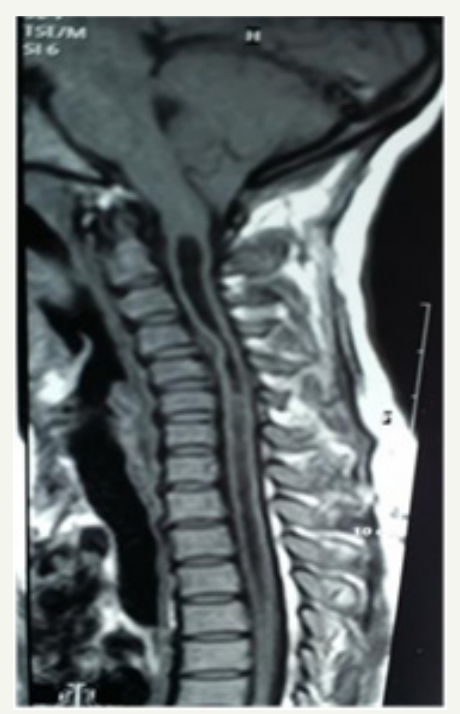

Figure 3: Sagittal T1-weighted MR image of the craniocervical \& upper thoracic spine showing herniation of cerebellar tonsils and a low-lying obex characteristic of Chiari malformation.

The pathologist Hans Chiari is the first one described Chiari type 1-malformation (CM-1) in 1981 as a caudal descent of the cerebellar tonsils passing through the foramen magnum to the spinal canal at least $5 \mathrm{~mm}$ below the inferior lip of the foramen magnum without involving the brain stem with non-communicating hydrocephalus in some cases. Syringomyelia is seen in $32-73 \%$ of cases with CM-I (Figure $3 \& 4$ ). This anatomical change can be seen as a result of obstruction of cerebrospinal fluid (CSF) outflow [1-7].

In this study, 20 patients had been diagnosed as Chiari type 1 primarily were studied prospectively to assess the value of the surgical management by posterior fossa bony decompression and cautious durotomy, shrinkage of the tonsils and duroplasty with fascia lata graft in the clinical and radiological improvement. Chiari type 1 malformation was found to affect females more than males as it showed 12 females (60\%) were affected against 8 males (40\%), with a female/male ratio 1.5/1. This results like Juan et al. [12] results in 2001 that reported female predominance [12]. Also in current study, age distribution ranged between 18 to 30 years in 10 patients $(50 \%)$, six patients $(30 \%)$ were in the age group, which extended from 41 to 50 years which coincident with Juan et al. [12] that reported most of cases were adolescent [12].

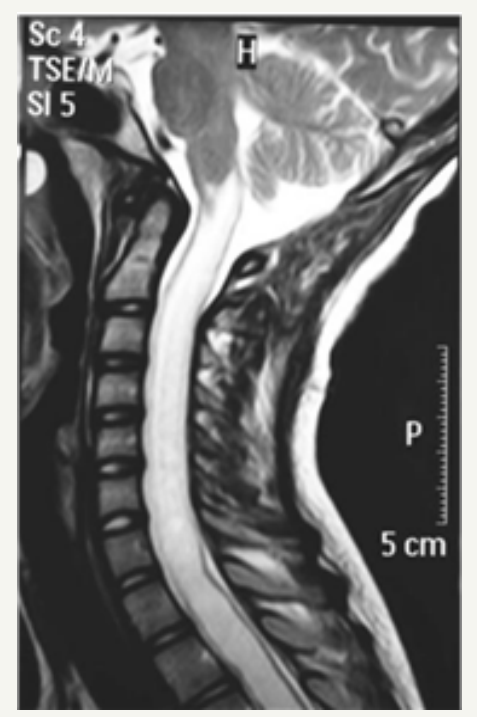

Figure 4: T2-weighted MR images of the spinal cord showing a holocord syrinx.

In this study, the most common clinical findings presented at diagnosis were headache in 20 patients, neck pain in 18 patients, dizziness and fatigue in 14 cases, extremities numbness and parathesia in 12 cases and these results were coincident with Kamal [11] study in which headache occurred in $100 \%$ of cases, neck pain in $89 \%$ of cases, dizziness and fatigue in $83 \%$, numbness in $72 \%$ [11].

In an evaluation of symptomatic outcome after decompression surgery for Chiari type I malformation, forty to eighty-five percent of patients present with suboccipital or occipital headaches, frequently exacerbated by cough or valsalva or cough [13]. Zhang ZQ [14] reported incidence of CM-1 is $0.5-0.77 \%$ based on large series of MRIs in retrospective study of 316 patients treated surgically but incidence increased with advances and increase utility of MRI especially in children [14]. In current study, sagittal T2 cut in MRI craniocervical junction was the gold standard in diagnosis. The American Association of Neurological Surgeons (AANS) reports that syringomyelia and Chiari are often misdiagnosed clinically as Chiari and syringomyelia are frequently mistaken for chronic fatigue syndrome or fibromyalgia and this make challenging in diagnosis and treatment also chronic headaches and muscle weaknesses in some cases can be treated as psychosomatic symptoms [15]. 
Ghassan Bejjani [16] reported that "real psychological problems can happened in some patients of Chiari if they are undiagnosed for long time and this complicate the treatment more [16]. In this study, 12 patients reported marked improvement after surgery, 4 reported fair improvement $\& 4$ were poor.

This is close to Mueller et al. [17] in which 84\% report marked and fair improvement [17]. Since Dr. Hans Chiari 1891 described Chiari type 1 malformation, many surgical procedures has been advocated for treatment of this condition, posterior fossa osseous decompression was mandatory needed either alone or in addition to many other techniques as: durotomy, duroplasty, dissection of the arachnoid bands and the outlet foramina of 4 th ventricle, obex plugging, tonsillar shrinkage or resection [3].

Syringomyelia associated with Chiari type 1 malformation has a debate regarding the ideal procedure required for treatment as plugging of the obex \& placement of syringe-peritoneal shunt [18]. Yet, craniocervical decompression became the preferred procedure as it is directed toward permanent elimination for the pathophysiology of this disorder with least risk [19].

In this prospective study, posterior fossa decompression, durotomy, tonsillar shrinkage until restoration of its normal level and duroplasty with fascia lata was performed to all patients.

Regarding the extent of osseous resection, Sindou et al. [20] proposed wide posterior fossa craniectomy with extreme lateral resection of the posterior edges of the foramen magnum to the occipital condyles then duroplasty without manipulation of the arachnoid, reporting good results and minimal complication [20]. Klekamp et al. [3], advocated much better results by small posterior fossa craniectomy with great importance preventing subsequent risk of cerebellar subsidence and symptoms recurrence [3].

Krieger et al. [21] recommended durotomy without duroplasty with comparing results to other authors who insisted the duroplasty to prevent postoperative scarring with maintaining integrity of CSF flow around foramen magnum and this was achieved in our study by grafting using fascia lata which is preferred than pericranial graft as it provides good area for dural grafting allowing enough room by its redundancy in the craniocervical area [21].

Although, arachnoid dissection is not recommended by some authors who preferred to leave the arachnoid intact to prevent spillage of blood into the subarachnoid space then arachnoiditis and readhesion [20]. Yet, these procedure was recommended by many authors who clarified the importance of arachnoid opening and dissection of arachnoid bands in the area of foramen magnum to allow free flow of CSF through outlet foramina of 4th ventricle [22].

Vidal CH [23] reported better results and less complications in patients treated by bony and dural decompression only without any violation to the arachnoid after comparison in 32 patients divided into 2 groups, first group treated with decompression without arachnoid violation and the second with tonsils manipulation and magendi opening [23].
Sub-pial tonsillar resection although reported to have good results in improving the volume mismatch of the posterior fossa, was not attempted in this study and substituted with induction of tonsillar shrinkage by bipolar coagulation of the preserved pial covering of the tonsils, giving highly comparable results without risk of arterial injury e.g. PICA [24].

Plugging of the obex was previously suggested relying on the hydro-dynamic theory of Gardner for treating associated syringomyelia [25], but recently it was found to be ineffective treatment in addition to its risk of brain stem injury, hence the procedure was excluded from our study reporting good results without any additional procedure in our scoop of follow up of the study.

In a retrospective analyzed consecutive series of 66 patients (mean patient age 15 years, range 1-53 years) done in Department of Pediatric Neurosurgery, Beth Israel Medical Center, Singer Division, New York by Juan C Alzate et al. [12]. The uniform posterior craniovertebral decompression, microsurgical reduction of the cerebellar tonsils, and dural closure using synthetic graft [12]. In Juan et al. [12] study, 32 patients presented by Chiari I malformation alone, and in 34 patients it was present in combination with syringomyelia. Clinical findings included pain, neurological deficits, and spinal deformity. The presence of syringomyelia was significantly associated with the presence of scoliosis [12].

In 22 of the 34 patients with syringomyelia, a syringosubarachnoid shunt was also placed. The mean follow-up period was 24 months (range 3-95 months). Excellent outcome was achieved in 54 patients (82\%) and good outcome in 12 (18\%). In no patient were symptoms unchanged or worse at followup examination, including four patients who initially required a second operation for persistent syringomyelia. Pain was more likely to resolve than sensory and motor deficits after decompressive surgery [12]. Radiological examination revealed normalization of tonsillar position in all patients. The syrinx had disappeared in 15 cases, was decreased in size in 17 , and remained unchanged in two [12].

The treatment of type 1 Chiari malformation (CM-1) with posterior fossa decompression without (PFD) or with duraplasty (PFDD) is in debate. Analysis study by Shweikeh F [26] included a national sample of $\mathrm{CM}-1$ patients operated between 2000 and 2009, 1593 patients underwent PFDD while 1056 patients underwent PFDD with conclusion of higher risk of complications and reoperatios and economic cost in PFDD than PFD. Overall, this study reveals that PFD is more favorable for $\mathrm{CM}-1$, though it would be prudent to conduct a prospective trial, as this analysis is limited by data on preoperative presentations and long-term outcomes [26].

In a study done by Deng X et al. [27] including 152 patients diagnosed as CMI who received Small-bone-window posterior fossa decompression (SPFD) starting from January 2008 to September 2009. All the patients underwent combined surgical procedures by a small-bone-window sub-occipital decompression (diameter, 
$2.5-3 \mathrm{~cm})$ and $\mathrm{C} 1$ laminectomy $(1.5-2 \mathrm{~cm}$ wide) then duraplasty with an autologous graft. Clinical assessment, radiological features and follow-up data through a six-year span were analyzed with average follow-up time was 74 months. Symptoms improved in 126 patients (82.9\%), stay stationary in 21 patients $(13.8 \%)$, and more deterioration in 5 patients $(3.3 \%)$ with no reported mortality. Postsurgical magnetic resonance (MR) images were done in all patients. Preoperatively MRI of 112 patients showed syringomyelia (SM), and the follow-up MR images documented obvious reduction of these syrinx in 73 patients (65.2\%) and 39 patients (34.8\%) has no significant change. Additionally, was observed in 92 patients (85.2\%) showed cistern magna enlargement [27].

In current study, we had CSF leak and wound infection in only one case with no neurological deficits post-operatively, no instability no need for resurgery and no mortality and these results coincident with results of Deng X and Kamal [13,27].

\section{Conclusion}

CM-1 can be managed safely with posterior fossa decompression with duroplasty using fascia lata after electrocautery of the tonsils followed by water tight closure of the dura and this procedure has less complications and mortality when it is done by perfect skilled hand surgeon in well qualified hospital.

\section{References}

1. Rosenbaum RB, DP Ciaverella (2004) Neurology in Clinical Practice. Butterworth Heinemann pp. 2192-2193.

2. Goel A, Bhatjiwale M, Desai K (1998) Basilar invagination: a study based on 190 surgically treated patients. J Neurosurg 88(6): 962-968.

3. Klekamp J, Batzdorf U, Samii M, Bothe HW (1996) The surgical treatment of Chiari 1 malformation. Acta Neurochir (Wein) 138(7): 788-801.

4. Milhorat TH, Chou MW, Trinidad EM, Kula RW, Mandell M, et al. (1999) Chiari malformation redefined: clinical and radiographic findings for 364 symptomatic patients. Neurosugery 44(5): 1005-1017.

5. Paul KS, Lye RH, Strang FA, Dutton J (1983) Arnold-Chiari malformation. Review of 71 cases. J Neurosurg 58(2): 183-187.

6. Vanaclocha V, Saiz-Sapena N (1997) Duroplast with freezedried cadaveric dura versus occipital pericranium for Chiari type 1malformation: comparative study. Acta Neurochir (Wein) 139: 112119.

7. Vanaclocha V, Saiz-Sapena N, Garcia-Casasola MC (1997) Surgica technique for craniocervical decompression in syringomyelia associated with Chiari type 1 malformation. Acta Neurochir (Wein) 139(6): 529539.

8. Tubbs RS, Iskandar BJ, Bartolucci AA, Oakes WJ (2004) A critical analysis of the Chiari 1.5 malformation. J Neurosurg 101(2 Suppl): 179-183.

9. Tubbs RS, McGirt MJ, Oakes WJ (2003) Surgical experience in 130 pediatric patients with Chiari 1 malformations. J Neurosurg 99(2): 291296.

10. Siasios J, Kapsalaki EZ, Fountas KN (2012) Surgical management of patients with Chiari 1 malformation. Int J Pediatr 2012: 640127.

11. Hazem M Kamal (2009) Management of Chiari malformation type 1. Egyptian Journal of Neurosurgery 24: 19-30.
12. Alzate JC, Kothbauer KF, Jallo GI, Epstein FJ (2001) Treatment of Chiari type 1 malformation in patients with and without syringomyelia: a Consecutive series of 66 cases. Neurosurg Focus 11(1): E3.

13. Kalb S, Perez-Orribo L, Mahan M, Theodore N, Nakaji P, et al. (2012) Evaluation of operative procedures for symptomatic outcome after decompression surgery for Chiari type 1 malformation. J Chin Neurosci 19(9): 1268-1272.

14. Zhang ZQ Chen YQ, Chen YA, WuX, Wang YB (2008) Chiari 1 malformation associated with syringomyelia: a retrospective study of 316 surgically treated patients. Spinal Cord 46(5): 358-363.

15. Haroun RI, Guarnieri M, Meadow JJ, Kraut M, Carson BS (2000) Current opinions for the treatment of syringomyelia and Chiari malformation: survey of the Pediatric Section of the A merican Association of Neurological Surgeons. Pediatr Neurosurg 33(6): 311-317.

16. Bejjani GK (2003) Association of the Adult Chiari Malformation and Idiopathic Intracranial Hypertension; more than a coincidence. Med Hypotheses 60(6): 859-863.

17. Diane Mueller, John J (2005) Prospective analysis of self-perceived quality of life before and after posterior fossa decompression in 112 patients with Chiari malformation with or without syringomyelia. Neurosurgical Focus 18(2): 1-6

18. Iwasaki Y, Hida K, Koyanagi I, Abe H (2000) Reevaluation of syringe subarachnoid shunt for syringomyelia with Chiari malformation. Neurosurgery 46(2): 407-412.

19. Oldfield EH (2002) Cerebellar tonsils and syringomyelia. J Neurosurg 97(5): 1009-1010.

20. Sindou M, Cha vez-Machuca J, Hashish H (2002) Cranio-cervical decompression for Chiari type 1 malformation and adding extreme lateral foramen magnum opening and expanile duroplasty with arachnoid preservation. Technique and long-term functional results in 44 consecutive adult cases comparison with literature data. Acta Neurochir (wien) 144(10): 1005-1019.

21. Krieger MD, Mccomb JG, Levy ML (1999) Toward a simpler surgical management of Chiari 1 malformation in a pediatric population. Pediatr Neurosurg 30(3): 113-121.

22. Munshi I, Firm D, Stine-Reyes R, Weir BK, Hekmatpanah J, et al. (2000) Effect of posterior fossa decompression with and without duroplasty on Chiari malformation-associated hydromyelia. Neurosurgery 46(6): $1389-1390$

23. Vidal CH (2015) Surgical treatment of type 1 Chiari malformation: the role of Magendie's foramen opening e tonsils manipulation. Arg Neuropsiquiatr 73(2): 179.

24. Guyotat J, Bret P, Jouanneau E, Ricci AC, Lapras C (1998) Syringomyelia Associated with type 1 Chiari Malformation A 21-Year Retrospective Study on 75 Cases Treated by Foramen Magnum Decompression with a Special Emphasis on the Value of Tnsils Resection. Acta Neurochirurgica 140(8): 745-754.

25. Gardner WJ, Angel J (1959) The mechanism of syringomyelia and its surgical correction. Clin Neurosurg 6: 131-140.

26. Shweikeh F, Sunjaya D, Nuno M, Drazin D, Adamo MA (2015) National trends, complications and hospital charges in pediatric patients with Chiari malformation type 1 treated with posterior fossa decompression with and without duroplasty. Pediatr Neurosurg 50(1): 31-37.

27. Deng X, Yang C, Gan J, Wu L, Yang T, et al. (2015) Long term Outcomes After Small-Bone-Window Posterior Fossa Decompression and Duroplasty in adults with Chiari Malformation Type 1. World Neurosurg 84(4): 998-1004. 
Creative Commons Attribution 4.0 International License

For possible submissions Click Here

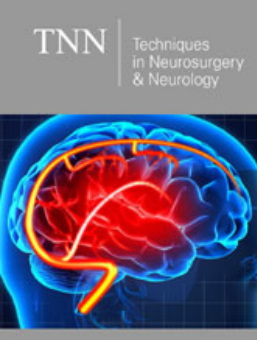

Techniques in Neurosurgery \& Neurology

Benefits of Publishing with us

- High-level peer review and editorial services

- Freely accessible online immediately upon publication

- Authors retain the copyright to their work

- Licensing it under a Creative Commons license

- Visibility through different online platforms 